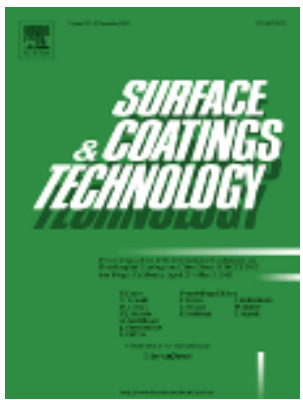

\title{
The effect of the angle of incidence on the aqueous corrosion of ion implanted M50 steel substrates
}

- C.M. Rangel,

- M.H. Simplicio,

- A.C.Consiglieri

- LNETI, Department of Materials Technology, P-1699 Lisboa Portugal

- B.R. Nielsen,

- B. Torp

- Danfysik, A/S, DK-4040 Jyllinge Denmark

- $\quad$ N. Teixeira,

- J.G. Alves,

- M.F. Silva

- LNETI, Department of Physics, P-2685 Sacavém Portugal

- J.C. Soares

- Centre of Nuclear Physics, U.L., P-1699 Lisboa Portugal

- A. Dodd,

- J. Kinder

- $\quad$ Bearing Research Centre, RHP Bearing Ltd, Newark, NG24 2JF UK

http://dx.doi.org/10.1016/0257-8972(92)90286-J 


\section{Abstract}

Following work on tantalum and chromium implanted flat M50 steel substrates, this work reports on the electrochemical behaviour of M50 steel implanted with tantalum and chromium and the effect of the angle of incidence.

Proposed optimum doses for resistance to chloride attack were based on the interpretation of results obtained during long-term and accelerated electrochemical testing. After dose optimization from the corrosion viewpoint, substrates were implanted at different angles of incidence $\left(15^{\circ}, 30^{\circ}, 45^{\circ}, 60^{\circ}, 75^{\circ}, 90^{\circ}\right)$ and their susceptibility to localized corrosion assessed using open-circuit measurements, step by step polarization and cyclic voltammetry at several scan rates $\left(5-50 \mathrm{mV} \mathrm{s}^{-1}\right)$.

Results showed, for tantalum implanted samples, an ennoblement of the pitting potential of approximately $0.5 \mathrm{~V}$ for an angle of incidence of $90^{\circ}$. A retained dose of $5 \times$ $10^{16}$ atoms $\mathrm{cm}^{-2}$ was found by depth profiling with Rutherford backscattering spectrometry. The retained dose decreases rapidly with angle of incidence. The breakdown potential varies roughly linearly with the angle of incidence up to $30^{\circ}$ falling fast to reach $-0.1 \mathrm{~V}$ (vs. a saturated calomel electrode (SCE)) for $15^{\circ}$.

Chromium was found to behave differently. Maximum corrosion resistance was found for angles of $45^{\circ}-60^{\circ}$ according to current densities and breakdown potentials. $\mathrm{Cr}^{+}$ depth profiles $((p, \gamma)$ resonance broadening method), showed that retained doses up to an angle of $60^{\circ}$ did not change much from the implanted dose at $90^{\circ}, 2 \times 10^{17} \mathrm{Cr}$ atoms $\mathrm{cm}^{-2}$.

The retained implantation dose for tantalum and chromium was found to follow a (cos $\theta)^{8 / 3}$ dependence where $\theta$ is the angle between the sample normal and the beam direction.

There are no figures or tables for this document.

Copyright (C) 1992 Published by Elsevier B.V. 